\title{
Effects of doping on structural, physical, and chemical properties of multiferroic $\mathrm{BiMnO}_{3}$ and $\mathrm{BiCrO}_{3}$
}

\author{
Alexei A. Belik and Eiji Takayama-Muromachi \\ International Center for Materials Nanoarchitectonics (MANA), National Institute for Materials Science (NIMS), \\ 1-1 Namiki, Tsukuba, Ibaraki 305-0044, Japan \\ Fax: 81-29-860-4674, e-mail: Alexei.Belik@nims.go.jp
}

\begin{abstract}
Effects of isovalent substitutions in the $\mathrm{Mn}(\mathrm{Cr})$ - and $\mathrm{Bi}$-sublattices of $\mathrm{BiMnO}_{3}$ and $\mathrm{BiCrO}_{3}$ on the magnetic, structural, and chemical properties have been studied. Phase diagrams in the whole compositional range were constructed for $\mathrm{BiMn}_{1-\mathrm{x}} \mathrm{Sc}_{\mathrm{x}} \mathrm{O}_{3}, \mathrm{BiMn}_{1-\mathrm{x}} \mathrm{Cr}_{\mathrm{x}} \mathrm{O}_{3}$, and $\mathrm{Bi}_{1-\mathrm{x}} \mathrm{R}_{\mathrm{x}} \mathrm{MO}_{3}(\mathrm{R}=\mathrm{Y}$ and $\mathrm{La}, \mathrm{M}=\mathrm{Cr}$ and $\mathrm{Mn}$ ). $\mathrm{BiMn}_{1-\mathrm{x}} \mathrm{Sc}_{\mathrm{x}} \mathrm{O}_{3}$ and $\mathrm{BiMn}_{1-\mathrm{x}} \mathrm{Cr}_{\mathrm{x}} \mathrm{O}_{3}$ keep the monoclinic $\mathrm{C} 2 / \mathrm{c}$ structure at RT for all $\mathrm{x}$ values; a spin-glass transition was found for $\mathrm{x} \geq 0.4$ in $\mathrm{BiMn}_{1-\mathrm{x}} \mathrm{Sc}_{\mathrm{x}} \mathrm{O}_{3}$ and at $\mathrm{x}=0.4$ and 0.5 in $\mathrm{BiMn}_{1-\mathrm{x}} \mathrm{Cr}_{\mathrm{x}} \mathrm{O}_{3}$. Magnetic phase diagrams of $\mathrm{BiMn}_{1-\mathrm{x}} \mathrm{Sc}_{\mathrm{x}} \mathrm{O}_{3}$ and $\mathrm{BiMn}_{1-\mathrm{x}} \mathrm{Cr}_{\mathrm{x}} \mathrm{O}_{3}$ are similar to each other for $\mathrm{x} \leq 0.5$. In $\mathrm{Bi}_{1-\mathrm{x}} \mathrm{R}_{\mathrm{x}} \mathrm{MO}_{3}$, the Pnma modification is stabilized very fast with $\mathrm{x}$; the Pnma phases show antiferromagnetic transitions with weak ferromagnetism.

Key words: Multiferroics, $\mathrm{BiMnO}_{3}, \mathrm{BiCrO}_{3}$, phase diagrams
\end{abstract}

\section{INTRODUCTION}

Multiferroics are an interesting class of materials from viewpoints of application and basic physics. ${ }^{1}$ In multiferroic systems, two or all three of (anti)ferroelectricity, (anti)ferromagnetism, and ferroelasticity are observed in the same phase. ${ }^{2} \mathrm{BiMnO}_{3}$ has been extensively studied as a multiferroic material. Three modifications of $\mathrm{BiMnO}_{3}$ exist at ambient pressure. ${ }^{3}$ The so-called phase I modification is stable below $474 \mathrm{~K}$, and its average structure is very well described by the $C 2 / c$ symmetry ${ }^{4}$ even though the local symmetry is lower. ${ }^{5,6}$ Phase I has the orbital order. The phase II modification is stable between 474 and $768 \mathrm{~K}$. Phase II has the same symmetry as that of phase I, however, it is believed that there is no orbital order in phase II. ${ }^{4}$ The orthorhombic $(\mathrm{O})$ modification (space group Pnma) is stable above $768 \mathrm{~K}$ and up to the decomposition temperature. $\mathrm{BiCrO}_{3}$ has two modifications: the first one has the phase II structure and the $C 2 / c$ symmetry (stable below $420 \mathrm{~K}$ ) and the second one has the Pnma symmetry. ${ }^{7}$

Heterovalent substitutions in the $\mathrm{Bi}$ sublattice of $\mathrm{BiMnO}_{3}$ have been investigated in a number of works. Transitions with different spin, charge, and orbital orders were found in $\mathrm{Bi}_{1-\mathrm{x}} \mathrm{M}_{\mathrm{x}} \mathrm{MnO}_{3}(\mathrm{M}=\mathrm{Ca}$ and $\mathrm{Sr})$. There is very limited information on isovalent substitution effects in $\mathrm{BiMnO}_{3}$ and $\mathrm{BiCrO}_{3}$.

In this work, effects of isovalent substitutions in the $\mathrm{Mn}(\mathrm{Cr})$ - and Bi-sublattices of $\mathrm{BiMnO}_{3}$ and $\mathrm{BiCrO}_{3}$ on the magnetic, structural, and chemical properties will be discussed. Phase diagrams in the whole compositional range were constructed for $\mathrm{BiMn}_{1-\mathrm{x}} \mathrm{Sc}_{\mathrm{x}} \mathrm{O}_{3}, \mathrm{BiMn}_{1-}$. ${ }_{\mathrm{x}} \mathrm{Cr}_{\mathrm{x}} \mathrm{O}_{3}$, and $\mathrm{Bi}_{1-\mathrm{x}} \mathrm{R}_{\mathrm{x}} \mathrm{MO}_{3}(\mathrm{R}=\mathrm{Y}$ and $\mathrm{La}, \mathrm{M}=\mathrm{Cr}$ and $\mathrm{Mn})$.

\section{EXPERIMENTAL PART}

All the samples were prepared at high pressure of 6 GPa and 1273-1673 K. Magnetic properties were studied by $\mathrm{dc}$ and ac susceptibility and specific heat using
MPMS and PPMS Quantum Design instruments. Hightemperature phase transitions and thermal stability were studied using differential scanning calorimetry (DSC) and TG/DTA analysis.

\section{RESULTS and DISCUSSION}

3.1 Substitutions in the $\mathrm{Mn}(\mathrm{Cr})$-sublattice

Compositional dependence of the lattice parameters in the solid solutions $\mathrm{BiMn}_{1-\mathrm{x}} \mathrm{M}_{\mathrm{x}} \mathrm{O}_{3}(\mathrm{M}=\mathrm{Al}, \mathrm{Sc}, \mathrm{Cr}, \mathrm{Fe}$, and $\mathrm{Ga}$ ) is shown on Figure 1..$^{9}$ The results on these solid solutions show that phase II is stabilized very fast with increasing $\mathrm{x}$. It means that the orbital ordered phase I of $\mathrm{BiMnO}_{3}$ is rather unstable compared, for example, with the stability of orbital order in $\mathrm{LaMn}_{1-\mathrm{x}} \mathrm{Ga}_{\mathrm{x}} \mathrm{O}_{3}$. During the phase I to phase II transition, the $a$ parameter increases, and the $b$ and $c$ parameters and $\beta$ angle decrease for all the substitutions. The same changes of the lattice parameters were observed during the temperature-driven phase I to phase II transition in $\mathrm{BiMnO}_{3}{ }^{3}$ It means that the temperature-driven and composition-driven phase I to phase II transitions have the same nature.

Figure 2a shows the DSC curves of $\mathrm{BiMnO}_{3}$ and $\mathrm{BiMn}_{0.95} \mathrm{Ga}_{0.05} \mathrm{O}_{3}$ with the phase I structure. ${ }^{9}$ The temperature of orbital ordering $T_{\mathrm{OO}}$ drops by $60 \mathrm{~K}$ with substitution of $5 \% \mathrm{Ga}$. Figure $2 \mathrm{~b}$ shows the magnetic susceptibility curves for the same samples, the ferromagnetic transition temperature $T_{\mathrm{C}}$ decreases only by $3 \mathrm{~K}^{9}{ }^{9}$ It means that as long as the orbital-ordered phase I is stable, the $T_{\mathrm{C}}$ changes a little. However, as soon as the phase II is stabilized, the $T_{\mathrm{C}}$ drops significantly (see the data for $\mathrm{BiMn}_{0.8} \mathrm{Ga}_{0.2} \mathrm{O}_{3}$ on Figure $2 \mathrm{~b}$ and also Figure 3 ). This fact may mean that the orbital order enhances the magnetic interactions and increases the $T_{\mathrm{C}}$.

Figure 3 gives the magnetic phase diagrams of $\mathrm{BiMn}_{1}$ ${ }_{x} \mathrm{Sc}_{\mathrm{x}} \mathrm{O}_{3}$ and $\mathrm{BiMn}_{1-\mathrm{x}} \mathrm{Cr}_{\mathrm{x}} \mathrm{O}_{3}$ where the solid solutions exist in the whole compositional range. ${ }^{10,11}$ It is interesting that at $0.0 \leq \mathrm{x} \leq 0.5$, the phase diagrams are very similar 


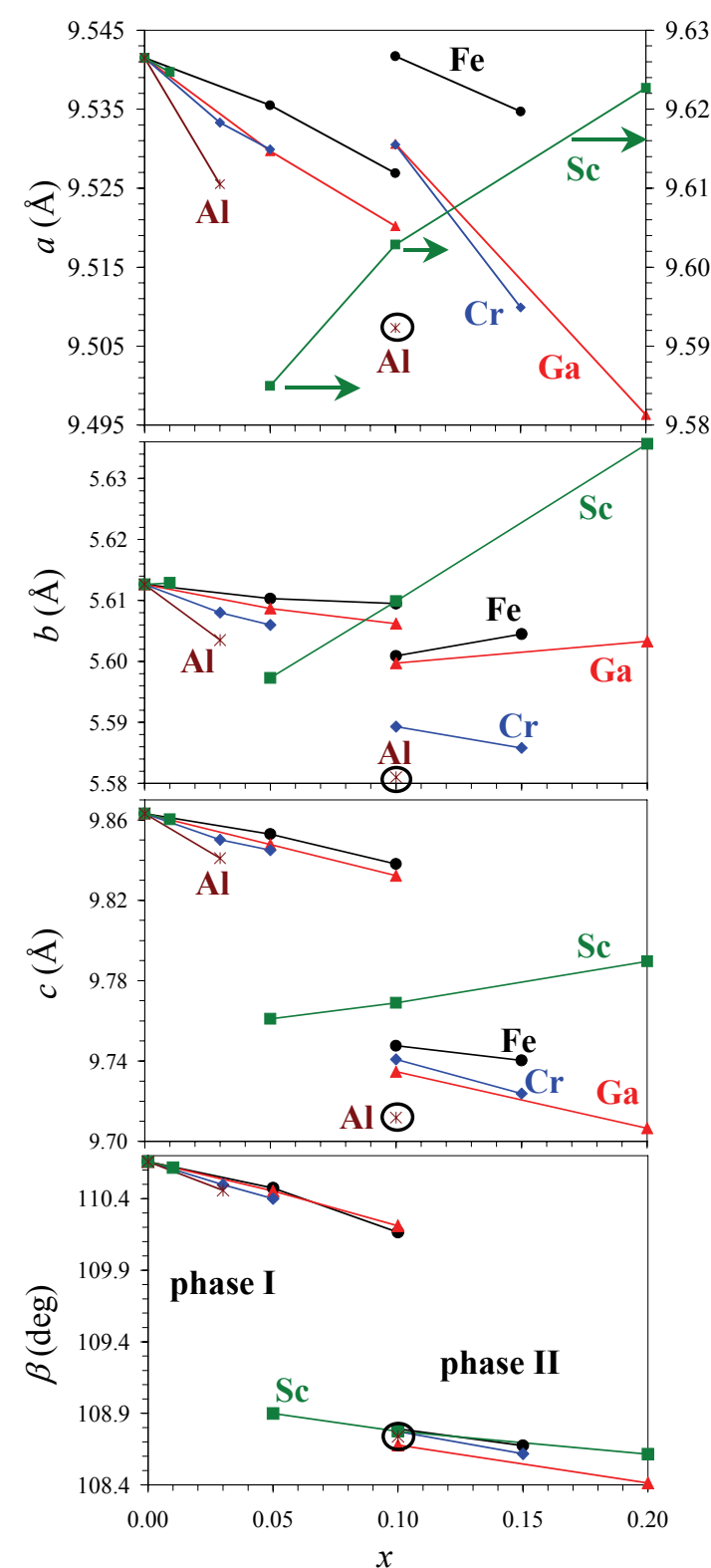

Fig. 1. Compositional dependence of the lattice parameters in solid solutions $\mathrm{BiMn}_{1-\mathrm{x}} \mathrm{M}_{\mathrm{x}} \mathrm{O}_{3}(\mathrm{M}=\mathrm{Al}$, $\mathrm{Sc}, \mathrm{Cr}, \mathrm{Fe}$, and $\mathrm{Ga}$ ) with the $C 2 / c$ symmetry. ${ }^{9,10}$ Note that the $a$ parameter for $\mathrm{M}=\mathrm{Sc}$ with $\mathrm{x} \geq 0.05$ is given using the right-hand axis.

to each other independent of the non-magnetic or magnetic substitution in the Mn-sublattice. With increasing $\mathrm{x}$, we observed the decrease of the $T_{\mathrm{C}}$, and the appearance of a re-entrant spin-glass (RSG) state at rather low temperatures. At $\mathrm{x}=0.4$ and 0.5 , a classical spin-glass (SG) transition was found (Figure 4). For $\mathrm{x} \geq$ 0.6 , the phase diagrams are, of course, different because $\mathrm{BiScO}_{3}$ is non-magnetic and $\mathrm{BiCrO}_{3}$ is an antiferromagnet (with weak ferromagnetism due to spin canting). ${ }^{7}$ Note that the RSG lines on the phase diagrams can be determined only with the ac susceptibilities because no anomalies were detected on the $\mathrm{dc}$ susceptibilities; ${ }^{10,11}$ and the real nature of the SG lines can also be determined with the ac susceptibility.
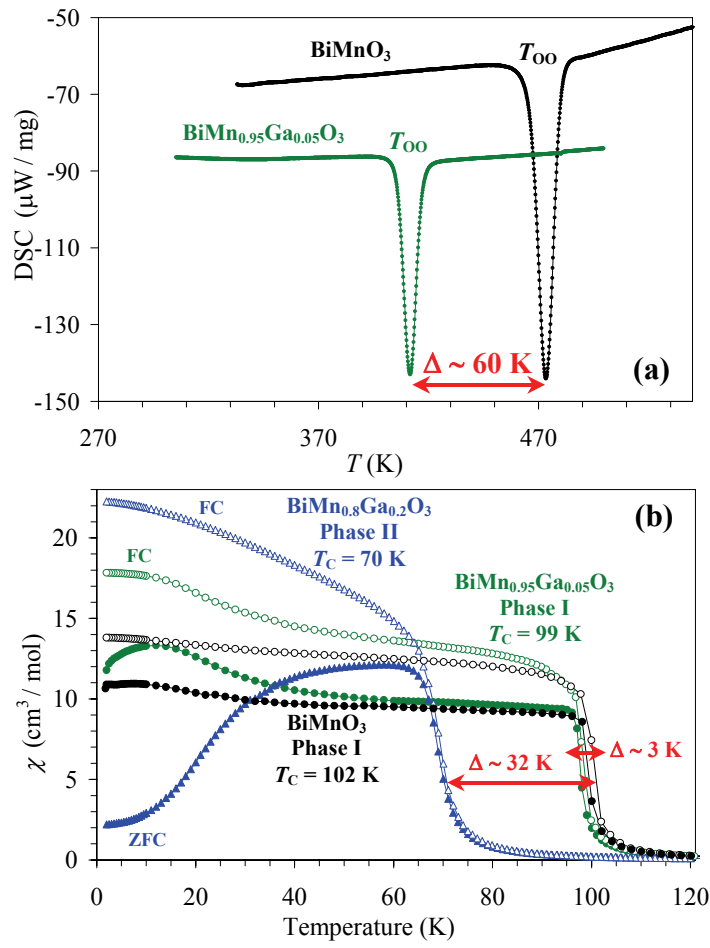

Fig. 2. (a) DSC curves of $\mathrm{BiMnO}_{3}$ and $\mathrm{BiMn}_{0.95} \mathrm{Ga}_{0.05} \mathrm{O}_{3}$ with the phase I structure in the vicinity of the orbital ordering temperature $T_{\mathrm{OO}} \cdot{ }^{9}$ (b) Magnetic susceptibilities (measured at $100 \mathrm{Oe}$ in the $\mathrm{ZFC}$ and $\mathrm{FC}$ modes) of $\mathrm{BiMnO}_{3}, \mathrm{BiMn}_{0.95} \mathrm{Ga}_{0.05} \mathrm{O}_{3}$, and $\mathrm{BiMn}_{0.8} \mathrm{Ga}_{0.2} \mathrm{O}_{3} .{ }^{9}$

\subsection{Substitutions in the Bi-sublattice}

Solid solutions $\mathrm{Bi}_{1-\mathrm{x}} \mathrm{La}_{\mathrm{x}} \mathrm{MnO}_{3}$ have been studied in a number of works. ${ }^{12}$ Our results showed that $\mathrm{Bi}_{0.95} \mathrm{La}_{0.05} \mathrm{MnO}_{3}$ contained a mixture of phase I (with $T_{\mathrm{C}}$ $\sim 100 \mathrm{~K}$ ) and phase II (with $T_{\mathrm{C}} \sim 85 \mathrm{~K}$ ). $\mathrm{Bi}_{0.9} \mathrm{La}_{0.1} \mathrm{MnO}_{3}$ contained a majority of phase II and traces of phase I. Because phases I and II are both ferromagnetic the presence of these phases can be easily detected by magnetic susceptibility measurements (Figure 5). $\mathrm{Bi}_{0.8} \mathrm{La}_{0.2} \mathrm{MnO}_{3}$ had a majority of the O-phase (with $T_{\mathrm{N}}=$ $80 \mathrm{~K}$ ) and traces of phase II. Because the O-phase has a ferromagnetic component its presence can also be easily detected by magnetic measurements (Figure 5). The $T_{\mathrm{N}}$ of O-phases increases with increasing $x$ in $\mathrm{Bi}_{1}$ ${ }_{\mathrm{x}} \mathrm{La}_{\mathrm{x}} \mathrm{MnO}_{3}$. Unfortunately, the $T_{\mathrm{OO}}$ of $\mathrm{Bi}_{1-\mathrm{x}} \mathrm{La}_{\mathrm{x}} \mathrm{MnO}_{3}$ cannot be determined because on heating in air, $\mathrm{Bi}_{1}$ ${ }_{x} \mathrm{La}_{\mathrm{x}} \mathrm{MnO}_{3}$ changes the oxygen content and, therefore, irreversibly changes the symmetry.

The O-phase is stabilized much faster in solid solutions $\mathrm{Bi}_{1-\mathrm{x}} \mathrm{Y}_{\mathrm{x}} \mathrm{MnO}_{3}$ where the O-phase is already observe at $\mathrm{x}$ $=0.1$. It means that the smaller the substituting ion the faster the O-phase appears. The $T_{\mathrm{N}}$ of O-phases decreases with increasing $\mathrm{x}$ in $\mathrm{Bi}_{1-\mathrm{x}} \mathrm{Y}_{\mathrm{x}} \mathrm{MnO}_{3}$ because $T_{\mathrm{N}}$ $=40 \mathrm{~K}$ in the $\mathrm{O}$-phase of $\mathrm{YMnO}_{3}$.

In $\mathrm{Bi}_{1-\mathrm{x}} \mathrm{La}_{\mathrm{x}} \mathrm{CrO}_{3}$ at $\mathrm{x}=0.05$, we found a new modification having an orthorhombic symmetry and a superstructure of $\sqrt{ } 2 a_{\mathrm{p}} \times 4 a_{\mathrm{p}} \times 2 \sqrt{2} a_{\mathrm{p}}$, where $a_{\mathrm{p}}$ is the parameter of the cubic perovskite subcell. Actually this superstructure is closely related to the phase II structure with the $C 2 / c$ symmetry as discussed for thin films of $\mathrm{BiScO}_{3} .{ }^{13} \mathrm{As}$ a results, magnetic properties of 

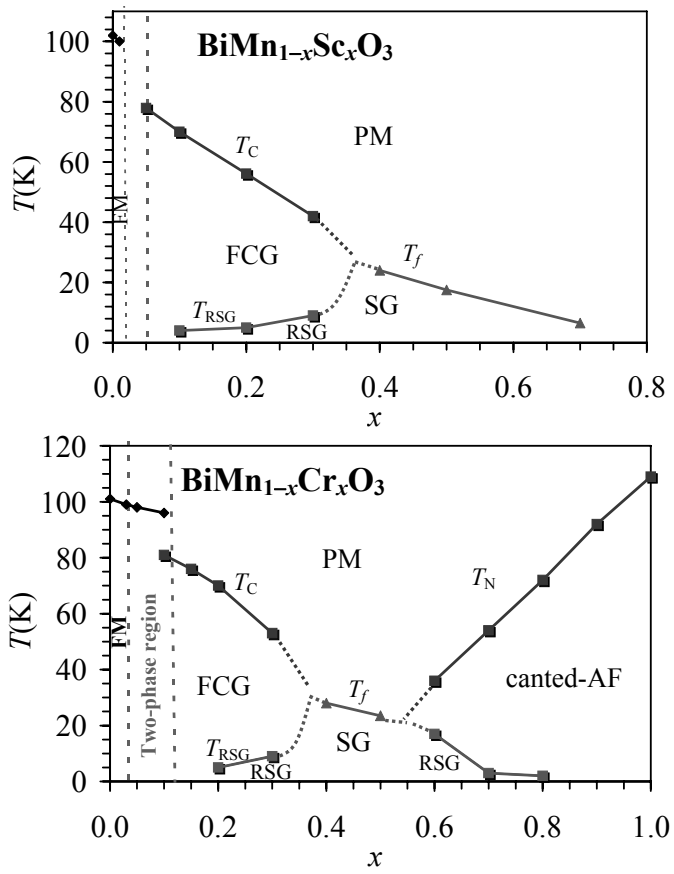

Fig. 3. Low-temperature (magnetic) phase diagrams of $\mathrm{BiMn}_{1-\mathrm{x}} \mathrm{Sc}_{\mathrm{x}} \mathrm{O}_{3}$ and $\mathrm{BiMn}_{1-\mathrm{x}} \mathrm{Cr}_{\mathrm{x}} \mathrm{O}_{3} \cdot{ }^{10,11}$ Vertical dash lines show two-phase regions where phases I and II coexist. PM: paramagnetic, FM: ferromagnetic with the Curie temperature $T_{\mathrm{C}}$, FCG: ferromagnetic cluster glass, RSG: re-entrant spin glass, SG: spin-glass with the freezing temperature $T_{f}$, AF: antiferromagnetic with the Neel temperature $T_{\mathrm{N}}$.

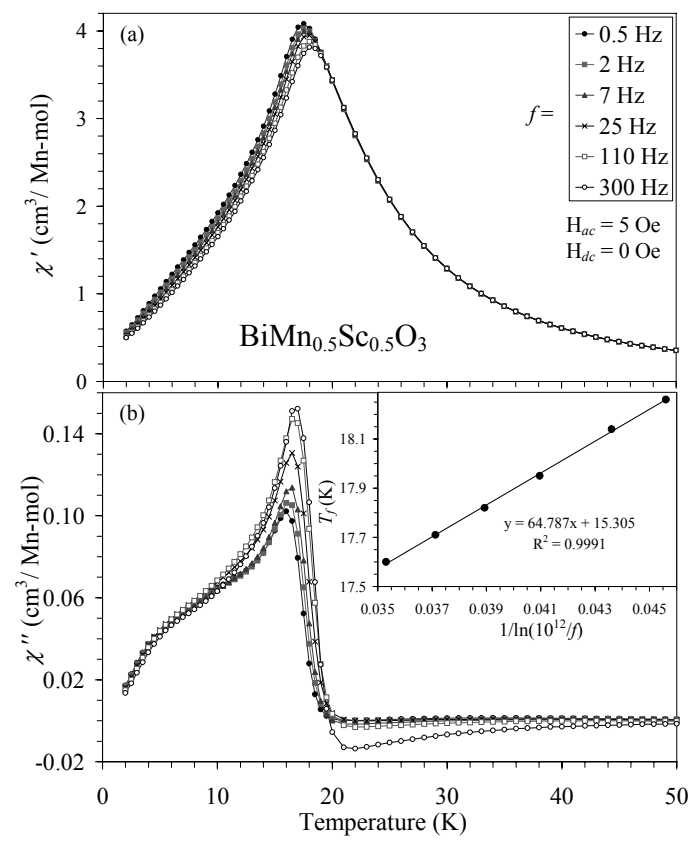

Fig. 4. Frequency dependence of the real $\left(\chi^{\prime}\right)$ and imaginary $\left(\chi^{\prime \prime}\right)$ parts of the ac susceptibilities of $\mathrm{BiMn}_{0.5} \mathrm{Sc}_{0.5} \mathrm{O}_{3}$ measured on cooling at $\mathrm{H}_{\mathrm{ac}}=5 \mathrm{Oe}$ and $\mathrm{H}_{\mathrm{dc}}=0$ Oe. Inset shows the fit to the Vogel-Fulcher law (the fitting parameters are $E_{\mathrm{a}} / \mathrm{k}_{\mathrm{B}}=64.8(9) \mathrm{K}$ and $T_{0}$ $=15.31(4) \mathrm{K}){ }^{1}$

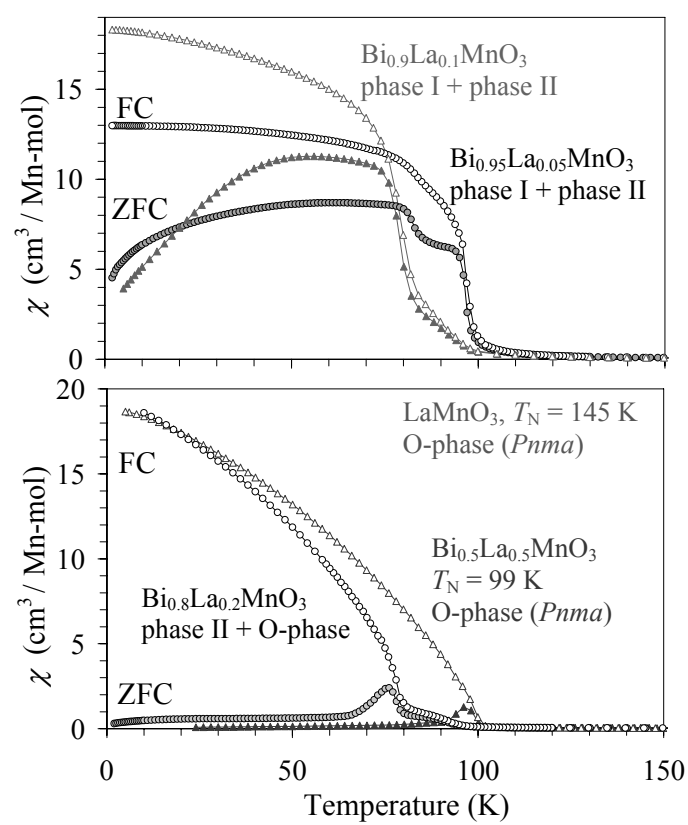

Fig. 5. dc magnetic susceptibilities (measured at 100 Oe in the ZFC and FC modes) of $\mathrm{Bi}_{0.95} \mathrm{La}_{0.05} \mathrm{MnO}_{3}$ (containing phases $\mathrm{I}$ and $\mathrm{II}$ ), $\mathrm{Bi}_{0.9} \mathrm{La}_{0.1} \mathrm{MnO}_{3}$ (containing phase II and traces of phase I), $\mathrm{Bi}_{0.8} \mathrm{La}_{0.2} \mathrm{MnO}_{3}$ (containing O-phase and traces of phase II), and $\mathrm{Bi}_{0.5} \mathrm{La}_{0.5} \mathrm{MnO}_{3}$ (containing O-phase). Note that the $T_{\mathrm{N}}$ of the O-phase increases with increasing the La content; the O-phase has a ferromagnetic component due to spin canting.

$\mathrm{Bi}_{0.95} \mathrm{La}_{0.05} \mathrm{CrO}_{3}\left(T_{\mathrm{N}}=120 \mathrm{~K}\right)$ are very similar with those of $\mathrm{BiCrO}_{3} \cdot \mathrm{Bi}_{0.8} \mathrm{La}_{0.2} \mathrm{CrO}_{3}$ has the O-phase as a majority phase, and $\mathrm{Bi}_{0.7} \mathrm{La}_{0.3} \mathrm{CrO}_{3}\left(T_{\mathrm{N}}=190 \mathrm{~K}\right)$ contained only the O-phase.

$\mathrm{Bi}_{0.95} \mathrm{Y}_{0.05} \mathrm{CrO}_{3}$ has the $\mathrm{O}$-phase as a majority phase and traces of monoclinic phase II, and $\mathrm{Bi}_{0.9} \mathrm{Y}_{0.1} \mathrm{CrO}_{3}\left(T_{\mathrm{N}}=\right.$ $155 \mathrm{~K}$ ) contained only the O-phase. All the O-phases are antiferromagnetic with weak ferromagnetism due to spin canting. The results on the substitution in the $\mathrm{Bi}$ sublattice of $\mathrm{BiCrO}_{3}$ are similar with those of $\mathrm{BiMnO}_{3}$ in a sense that the substituting ions with smaller ionic radii stabilize the O-phase faster (that is, at smaller $\mathrm{x}$ values).

As a conclusion, Figure 6 gives schematic comparison of the phase diagrams of $\mathrm{Bi}_{1-\mathrm{x}} \mathrm{La}_{\mathrm{x}} \mathrm{MnO}_{3}$ and $\mathrm{BiMn}_{1}$. ${ }_{x} \mathrm{Sc}_{\mathrm{x}} \mathrm{O}_{3}$. One general feature on these diagrams is a very narrow stability range of the monoclinic phase I with orbital order. In $\mathrm{BiMn}_{1-\mathrm{x}} \mathrm{Sc}_{\mathrm{x}} \mathrm{O}_{3}$, phase I is replaced by phase II with increasing $\mathrm{x}$. In $\mathrm{Bi}_{1-\mathrm{x}} \mathrm{La}_{\mathrm{x}} \mathrm{MnO}_{3}$ with $\mathrm{x} \geq$ 0.2 , the $\mathrm{O}$-phase is stable. Structural analysis at room temperature showed that the O-phases of $\mathrm{Bi}_{1-\mathrm{x}} \mathrm{La}_{\mathrm{x}} \mathrm{MnO}_{3}$ have the orbital order (that is, two long Mn-O bond lengths and two short Mn-O bond lengths) similar to the orbital order of $\mathrm{LaMnO}_{3}$. As already mentioned, the compositional dependence of $T_{\mathrm{OO}}$ in $\mathrm{Bi}_{1-\mathrm{x}} \mathrm{La}_{\mathrm{x}} \mathrm{MnO}_{3}$ could not be studied because of the change of the oxygen content on heating in air. However, an interesting question is the existence of orbital order in the O-phase of undoped $\mathrm{BiMnO}_{3}$ above $768 \mathrm{~K}$. 


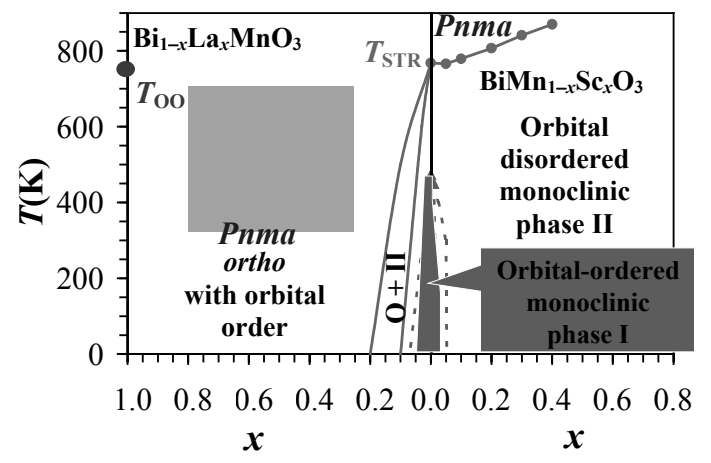

Fig. 6. Schematic comparison of the phase diagrams of $\mathrm{Bi}_{1-\mathrm{x}} \mathrm{La}_{\mathrm{x}} \mathrm{MnO}_{3}$ a nd $\mathrm{BiMn}_{1-\mathrm{x}} \mathrm{Sc}_{\mathrm{x}} \mathrm{O}_{3}$. The gen eral feature is a very narrow stability range of the monoclinic phase I. The grey part on the left means that the $T_{\mathrm{OO}}$ could not be determined because of the ch ange of the o xygen content. $T_{\mathrm{STR}}$ means the structural phase transition from the monoclinic to orthorhombic modification.

\section{Acknowledgements}

This work was supported by World Premier International Research Center (W IP) Initiative on Materials Nanoarchitectonics, MEXT, Japan and by the NIMS Individual-Ty pe Com petitive Research Grant. Modified figures 1 and 2 are published with the permission of the ACS.

\section{References}

[1] R. Ramesh and N. A. Spa ldin, Nat. Mater., 6, 21 (2007).

[2] N. A. Hill, J. Phys. Chem. B, 104, 6694 (2000).

[3] T. Kimura, S. Ka wamoto, I. Ya mada, M. Azuma, M. Takano and Y. Tokura, Phys. Rev. B, 67, 180401(R) (2003).

[4] A. A. Belik, S. Iikubo, T. Yokosawa, K. Kodama, N. Igawa, S. Shamoto, M. Azuma, M. Takano, K. Kimoto, Y. Matsui and E. Takayama-Muromachi, J. Am. Chem. Soc., 129, 971 (2007).

[5] T. Yokosawa, A. A. Belik , T. Asaka, K. Kimoto, E. Takayama-Muromachi and Y. Matsui, Phys. Rev. B, 77, 024111 (2008).

[6] K. Kodama, S. Iikubo, S. Shamoto, A. A. Belik and E. Takayama-Muromachi, J. Phys. Soc. Jpn., 76, 124605 (2007).

[7] A. A. Belik, S. Iikubo, K. Kodama, N. Igawa, S. Shamoto and E. Takay ama-Muromachi, Chem. Mater., 20, 3765 (2008).

[8] R. J. Goff a nd J. P. Attfield, J. Solid State Chem., 179, 1369-1374 (2006).

[9] A. A. Belik and E. Takay ama-Muromachi, Inorg. Chem., 46, 5585-5590 (2007).

[10] A. A. Belik, T. Yokosaw a, K. Kimoto, Y. Matsui and E. Takay ama-Muromachi, Chem. Mater., 19, 16791689 (2007).

[11] A. A. Belik, E. Takay ama-Muromachi, J. Phys .: Condens. Matter, 20, 025211 (2008).

[12] I. O. Troy anchuk, O. S. Manty tskaja, H. Szy mczak and M. Y. Shvedun, Low Te mp. P hys., 28, 569-573 (2002).

[13] S. Trolier-McKinstry, M. D. Biegalski, J. Wang, A.
A. Belik, E. Takay ama-Muromachi and I. Levin, $J$. Appl. Phys., 104, 044102 (2008).

(Received December 10, 2008 ; Accepted February 2, 2009) 